\title{
Paper \\ Electrode Constructions of High Pressure Sodium Lamp and Their Life Characteristics
}

\author{
Naoki SAITO* and Katsusuke MURAKAMI"* \\ *Consultant for Light Sources \\ ** Graduate School of Bioresources, Department of Environmental Science and Technology, Mie University
}

Received June 18, 2009, Accepted August 26, 2009

Paper originally presented at the 1978 Annual Conference of IEI Japan ${ }^{1)}$

\begin{abstract}
It is well known that the glow to thermionic-arc transition time of HID lamps when the lamp ignites has close relationship to lamp-life characteristics. High-pressure sodium lamps with five different electrode constructions filled with Ne-Ar Penning gas were used for experiments. It became clear that lighter electrode-weight with emitter had shorter glow to thermionic-arc transition time and showed good life performance, as long as the emitter was shielded from the discharge space.
\end{abstract}

KEYWORDS: high pressure sodium lamp, electrode construction, glow to arc transition time, electrode weight, life performance

\section{Introduction}

There are some papers concerning the phenomena immediately after the ignition ${ }^{2)-6)}$ of the lamp. These papers report ignition phenomena with theoretical analysis and/or calculation.

For the saturated HID lamp such as HPS lamp, glow to arc transition time is very important from the point of life performance. If glow to arc transition time continues long, sputtering from electrodes such as emitter and tungsten causes severe blackening near the ends of the arc tube. This leads to higher temperature of the coldest spot of the arc tube. This means rising of lamp voltage and lower lumen maintenance.

It is known that smaller heat capacity of electrode brings shorter glow to arc transition time ${ }^{3)}$.

In this paper we report the result of experiments with five different constructions of electrodes for high pressure sodium lamp filled with $\mathrm{Ne}-\mathrm{Ar}$ Penning gas.

\section{Experimental setup}

We used HPS lamps $400 \mathrm{~W}$ with Ne-Ar Penning gas (Ne 99.5\% + Ar 0.5\%) for the experiment. Figure 1 shows the lamp shape and arc tube construction used for experiments. The arc tube with poly crystalline alumina was made with average grain size under $10 \mu \mathrm{m}$. Inner diameter of the arc tube was $8.5 \mathrm{~mm}$ and total length was $121 \mathrm{~mm}$. Arc length was $82 \mathrm{~mm}$ and electrodes were inserted $13.5 \mathrm{~mm}$ inside arc tubes. Five types of electrodes were tested as are shown in Table 1. The diameter of each electrode rod was the same

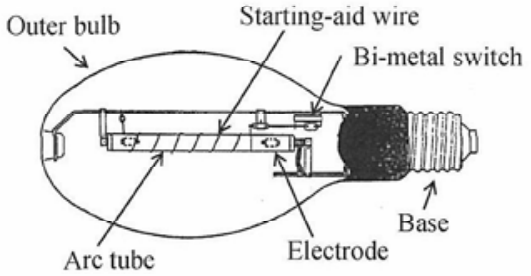

Construction of the lamp

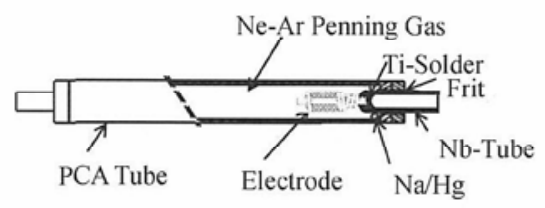

Construction of the arc tube

Figure 1 Lamp and arc tube construction used for experiments

Table 1 Electrodes used for experiment and their weight

\begin{tabular}{|c|c|c|c|c|c|c|c|}
\hline \multirow[t]{2}{*}{ code } & \multirow[t]{2}{*}{ Electrode } & \multirow{2}{*}{$\begin{array}{c}\text { Rod } \\
\text { (Diameter } \times \text { Length) }\end{array}$} & \multirow{2}{*}{$\begin{array}{c}\text { Coil } \\
\text { (Diameter x Turns) }\end{array}$} & \multicolumn{4}{|c|}{ Weight (g) } \\
\hline & & & & Rod & Coil & Emitter & Total \\
\hline A & c & $\phi 1.2 \times 11$ & $\phi 0.6 \quad 12 \times 9$ & 0.240 & 1.247 & 0.025 & 1.512 \\
\hline B & 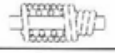 & $\$ 1.2 \times 11$ & $\phi 0.6 \quad 8 \times 9$ & 0.240 & 0.719 & 0.038 & 0.997 \\
\hline C & เมบบนเ & $\phi 1.2 \times 11$ & Triple Coil & 0.240 & 0.079 & 0.068 & 0.387 \\
\hline$D$ & ता & $\phi 1.2 \times 11$ & $\begin{array}{c}\text { Outer Coil } \\
\phi 0.612 \times 9 \\
\text { Inner Coil } \\
\phi 0.410 \times 10\end{array}$ & 0.240 & $\begin{array}{l}0.667 \\
0.337\end{array}$ & 0.028 & 1.272 \\
\hline$E$ & 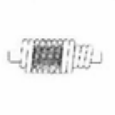 & $\phi 1.2 \times 11$ & $\begin{array}{l}\text { Outer Coil } \\
\phi 0.612 \times 9 \\
\text { Inner Coil } \\
\text { Triple coil }\end{array}$ & 0.240 & $\begin{array}{l}0.667 \\
0.069\end{array}$ & 0.061 & 1.037 \\
\hline
\end{tabular}


$(1.2 \mathrm{~mm})$ and total length was $11 \mathrm{~mm}$, and it protruded $1 \mathrm{~mm}$ from the coil.

\section{Electrode A}

Electrode $\mathrm{A}$ is constructed of tungsten wire (diameter $0.6 \mathrm{~mm}$ ) wound as two layers of $12 \times 9$ turns with the pitch of $0.6 \mathrm{~mm}$ around a tungsten rod. Electrodes were dipped into the emitter slurry and the emitter was brushed off from the surface of the coil and the electrode-tip after drying. Emitter in and on the coil was sintered.

\section{Electrode B}

Electrode B is nearly the same construction as that of electrode A. The different point of electrode B is doublepitched coil with first layer under the second layer. This space allowed more emitter weight, compared with those of electrode $\mathrm{A}$.

Electrode C

Electrode $\mathrm{C}$ is constructed with triple coil around electrode rod. Triple coil was wound as follows;

First coil: W wire $(22 \mu \mathrm{m})$ was wounded around two wires of $\mathrm{W}: 70.8 \mu \mathrm{m}$ and Mo: $104 \mu \mathrm{m}$ with the pitch of $60 \mu \mathrm{m}$.

Second coil: First coil above mentioned was wound around wire of $\mathrm{W}: 250 \mu \mathrm{m}$ with the pitch of $294 \mu \mathrm{m}$.

Third coil: Second coil mentioned above was wound 7 turns around electrode rod $(1.2 \mathrm{~mm})$.

Mo wire was removed by acid after coiling.

Triple coil was dipped into the slurry of emitter. Emitter was brushed off only from the tip of electrode rod.

\section{Electrode D}

Electrode D is constructed with the inner coil and outer coil. The characteristic of this electrode is that the emitter was held only in/on the inner coil. Inner coil is two layers of tungsten wire with the diameter of $0.4 \mathrm{~mm}$ and wound $10 \times 10$ turns. Outer coil was wound with the tungsten wire of diameter of $0.6 \mathrm{~mm}$, that is, 3 turns were wound around the rod and 10 turns were wound for holding the inner coil inside. Maximum diameter of outer electrode is $4 \mathrm{~mm}$. The top of outer coil was wound inside and held the inner coil.

\section{Wlectrode $\mathrm{E}$}

Electrode $\mathrm{E}$ is inner-outer type similar to that of elec trode D. Difference of the two is that the triple coil was used for electrode $\mathrm{E}$. The triple coil was the same as that of electrode $\mathrm{C}$, that is, triple coil 7 turns. The process for making electrodes was the same as that of electrode D. Emitter was only held in the inner triple coil. The top of outer coil was wound inside and held the in ner coil.

Electrodes were fixed with niobium tubes $(\phi 4, \mathrm{Nb}+$ $1 \% \mathrm{Zr}$ ) by titanium solder. Emitter slurry is mainly composed of $\mathrm{BaCO}_{3}-\mathrm{CaCO}_{3}-\mathrm{ThO}_{2}$. After dipping rod and coil with electrode A, B, C and inner coil of electrode D
Table 2 Total burning hours of lamps

\begin{tabular}{cccc}
\hline Electrode & $\mathrm{n}$ & burning hours $(\mathrm{h})$ & Remarks \\
\hline A & 3 & 21,186 & $\begin{array}{c}\text { Arc tubes caused crack } \\
\text { because of shortage of ballasts } \\
(15.731 \mathrm{~h} \& \text { 16.382h })\end{array}$ \\
\hline B & 3 & 21,186 & \\
\hline C & 3 & 13,407 & \\
\hline D & 2 & 21,186 & \\
\hline E & 3 & 26,244 & \\
\hline
\end{tabular}

and electrode $\mathrm{E}$ into the emitter slurry, they were dried and burned at high temperature in Argon atmosphere. Carbonates of emitter were changed to oxides. Emitter weight shown in Table 1 is at the state of oxides. Total weight is electrode weight (rod and coil) plus emitter weight.

Niobium tubes and PCA tubes were tightly sealed by the frit with the composition of $\mathrm{Al}_{2} \mathrm{O}_{3}-\mathrm{MgO}^{-} \mathrm{CaO}-\mathrm{BaO}^{-}$ $\mathrm{B}_{2} \mathrm{O}_{3}$. In the arc tube, sodium amalgam $58.6 \mathrm{mg}$ with sodium (mole-ratio 60\%) was sealed. As a starting-aid gas, Ne-Ar Penning gas (Ne 99.5\% + Ar 0.5\%) was sealed in the arc tube at the pressure of around $3 \times 10^{3} \mathrm{~Pa}$ ( 25 degree Centigrade). Wall temperature of the arc tube during operation was designed to be about 1,100 degree Centigrade operated at the rated lamp wattage $400 \mathrm{~W}$. Starting aid wire was wound around the arc tube as is shown in Figure 1 at the point of $10 \mathrm{~mm}$ away from the base-side electrode and was wound to the other electrode. The reason why staringaid wire was started at the position of $10 \mathrm{~mm}$ away from the electrode is because blackening near electrodes seemed to be within $10 \mathrm{~mm}$ during rated life-time. Stating-aid wire was connected with a bi-metal switch and potential voltage on starting-aid wire was added only at the ignition and was off during operation. Arc tubes were placed in clear elliptical bulbs with maximum diameter of $120 \mathrm{~mm}$. The inside of the bulb was highly evacuated with barium getters. Lamps of four kinds of electrodes were tested with three lamps, but two lamps were tested with electrode D.

These lamps were burned with the cycle of 5.5 hours on and 0.5 hour off. Burning position was horizontal. Ballasts for $400 \mathrm{~W}$ were inductive type $(200 \mathrm{~V}, 60 \mathrm{~Hz})$ with short-circuit current of $6.7 \mathrm{~A}$. Total burning hours of lamps with five kinds of electrodes are shown in Table 2 .

Glow to arc transition time was measured with inductive ballast of short-circuit current $3.98 \mathrm{~A}$, to make the difference clear between electrodes. After the ignition, glow discharge and arc discharge co-existed and then they showed only arc discharge. Here we call coexistence time of glow discharge and arc discharge as glow to arc transition time. 


\section{Life characteristics Electrode A}

Glow to arc transition time is shown in Figure 2(a). In the early stage of the burning, glow to arc transition time is around $3-6$ seconds and spread is small. With the increase of burning hours, it rises up and spread becomes wider. Around after the burning of 5,000 hours, blackening near both electrodes became gradually severe. These blackening were caused by the sputtering of electrode material such as tungsten and emitter. This means increase of the coldest spot temperature of the arc tube and consequently the increase of lamp voltage.

Variation of lamp voltage and lumen maintenance are shown in Figure 2(b) and Figure 2(c) respectively. Lamp voltage shows rapid increase after the burning of around 10,000 hours and lumen maintenance goes down nearly just as fast as lamp voltage increase. That is nearly the same tendency as that of glow to arc transition time gets longer.

\section{Electrode B}

Glow to arc transition time is shown in Figure 3(a). Variations of lamp voltage and lumen maintenance during burning are shown in Figure 3(b) and Figure 3(c) respectively. Lamp voltage goes up rapidly after around
10,000 hours burning and lumen maintenance goes down as lamp voltage goes up. These show the same tendency as that of electrode A.

\section{Electrode C}

Burning of lamps with electrode $\mathrm{C}$ were stopped around 13,400 hours. The reason was that lamps extinguished by high lamp voltage.

Glow to arc transition time is shown in Figure 4(a). This shows short time of around 1 - 3 seconds and showed nearly the same time during operation up to around 13,400 hours. The spread of transition time was small. In spite of short transition time, lamp voltage went up rapidly as is shown in Figure 4(b). Both ends of the arc tube caused hard blackening. The reason is as follows; the temperature of emitter was too high during burning and cathode fall near electrode at ignition period caused severe sputter. Lumen maintenance is shown in Figure 4(c). Lumen maintenance goes down after burning of around 7,000 hours.

\section{Electrode D}

Figure 5(a) shows the glow to arc transition time of electrode D. Glow to arc transition time becomes longer after about 4,000 hours burning, and lamp voltage began to increase around the same time, as is shown in
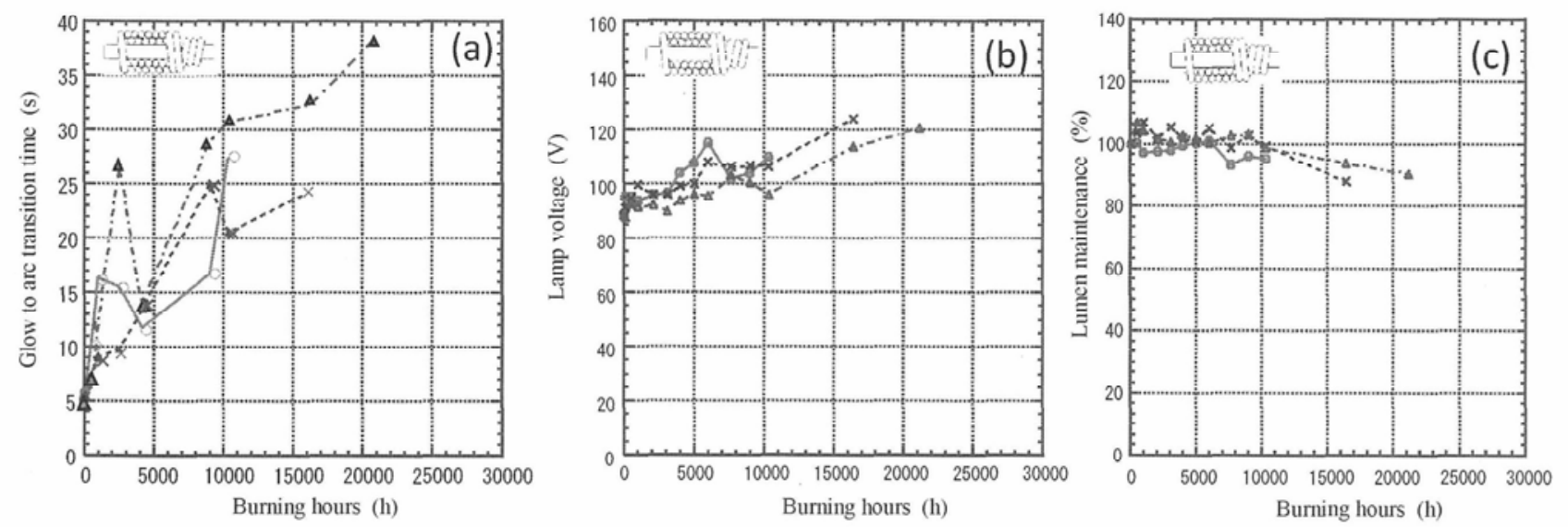

Figure 2 Variation of glow to arc transition time (a), lamp voltage (b) and lumen maintenance (c) with electrode A during operation ( $\mathrm{n}=3$ )
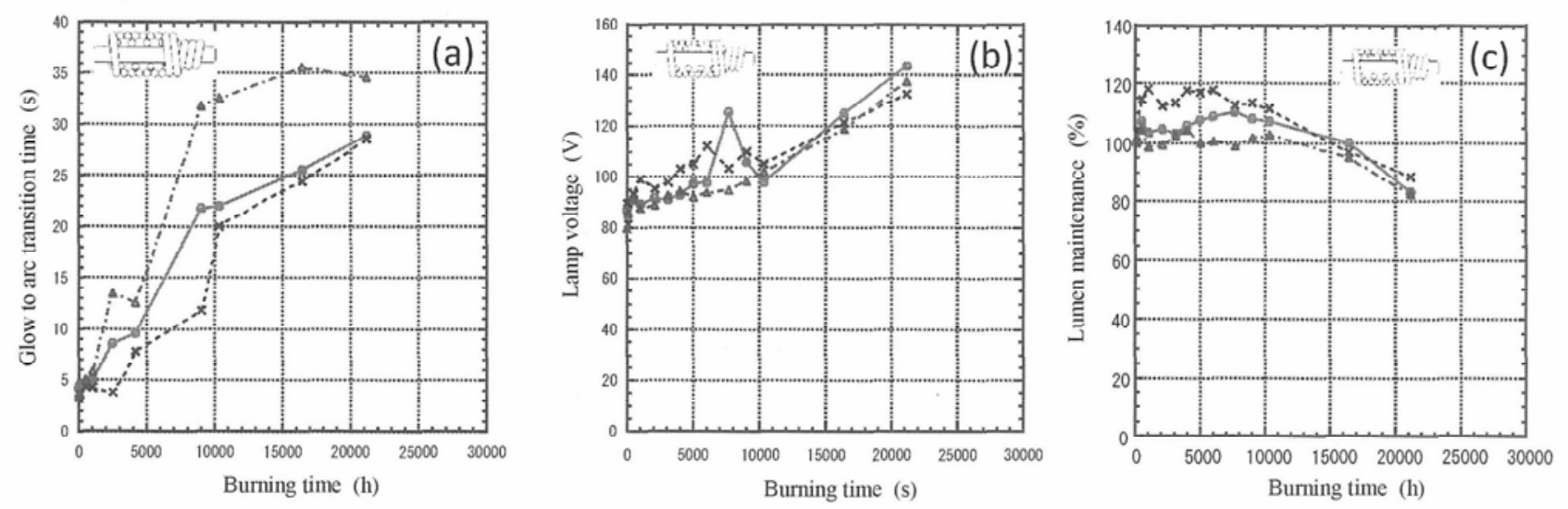

Figure 3 Variation of glow to arc transition time (a), lamp voltage (b) and lumen maintenance (c) with electrode B during operation ( $\mathrm{n}=3$ ) 

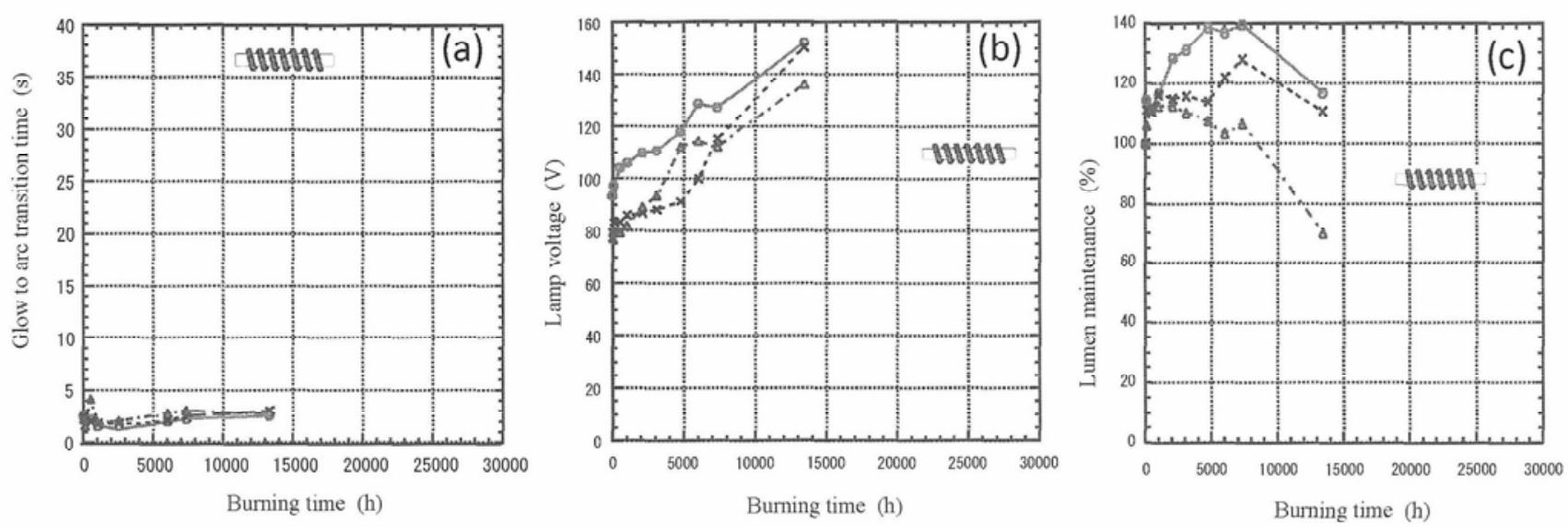

Figure 4 Variation of glow to arc transition time (a), lamp voltage (b) and lumen maintenance (c) with electrode $C$ during operation ( $n=3$ )
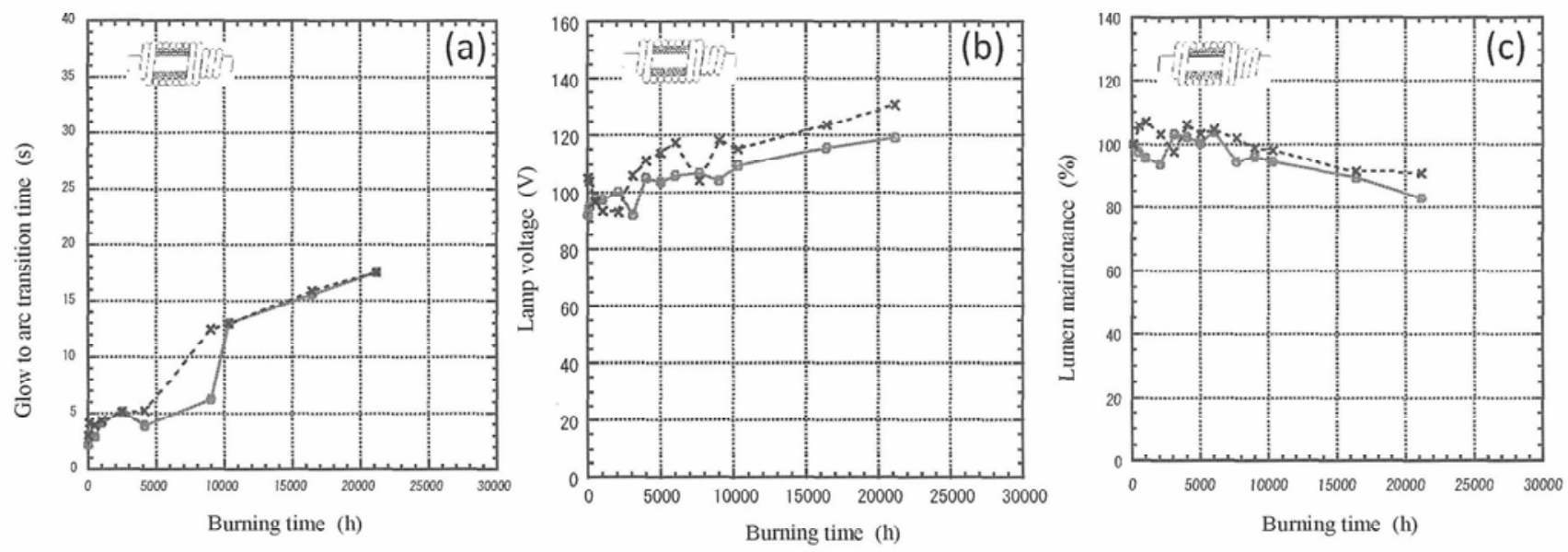

Figure 5 Variation of glow to arc transition time (a), lamp voltage (b) and lumen maintenance (c) with electrode $D$ during operation ( $\mathrm{n}=2$ )
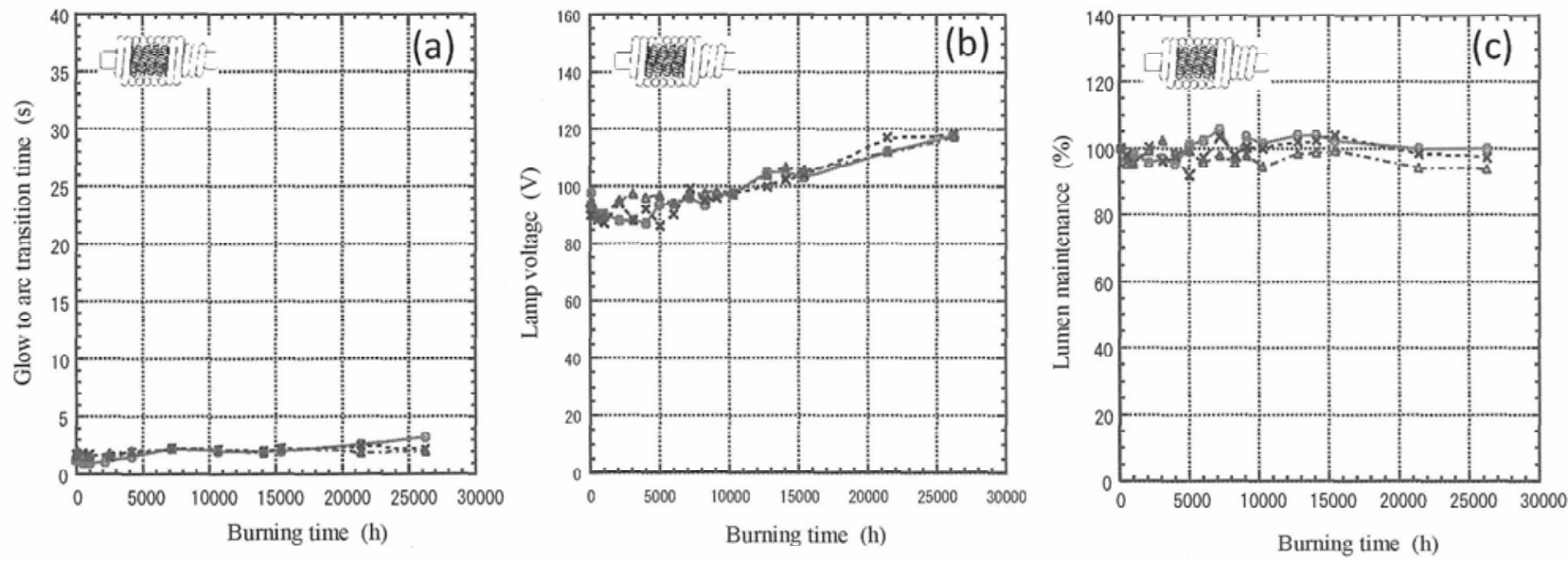

Figure 6 Variation of glow to arc transition time (a), lamp voltage (b) and lumen maintenance (c) with electrode $E$ during operation ( $n=3$ )

Figure 5(b). Lamp voltage seems to go up after around 4,000 hours burning. With it, lumen maintenance goes down monotonically, as is shown in Figure 5(c).

Electrode E

The glow to arc transition time of electrode $\mathrm{E}$ is shown in Figure 6(a). The glow to arc transition time showed nearly the same value after burning of around
26,000 hours, compared with those of initial stage. The spread is small and they were under 5 seconds even after burning of 26,000 hours. The variation of lamp voltage is shown in Figure 6(b). This showed nearly the same value within 6,000 hours burning and began to increase gradually with burning hours. Blackening around electrodes was small. Lumen maintenance 
showed nearly $100 \%$ during the burning hours, as is shown in Figure 6(c).

\section{Discussion}

As is shown above, electrode construction has big influence on life performance of high pressure sodium lamp. Figure 7 shows the relation between electrode weight and glow to arc transition time of initial lamp. There are two groups, that is, one is the group shown by line in Figure 7 including electrode A, electrode B and electrode $\mathrm{C}$ where the emitter is exposed directly to the discharge space. The other shown by broken line in

Oh

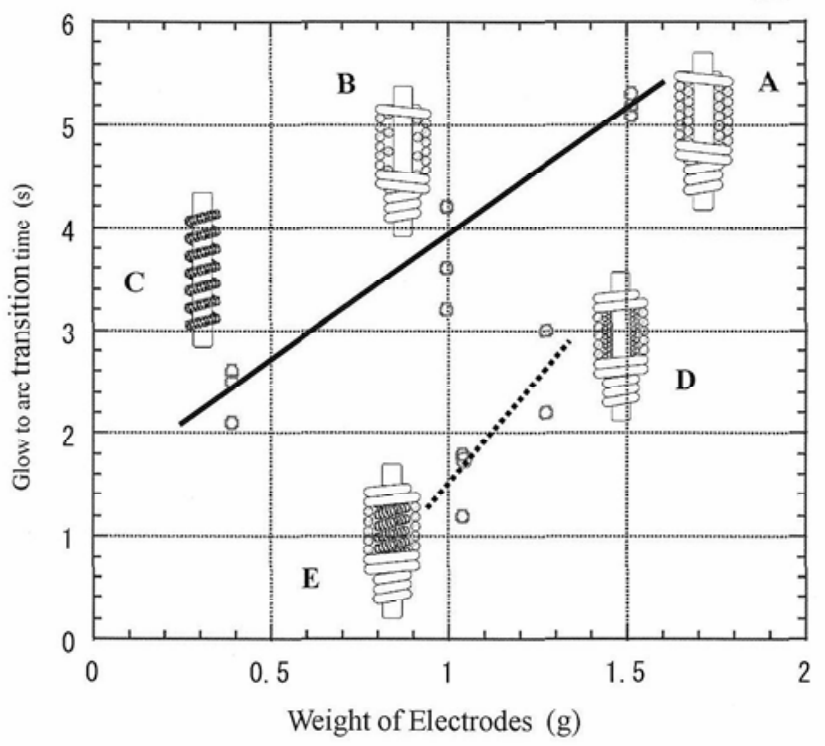

Figure 7 Relationship between electrode weight and glow to arc transition time

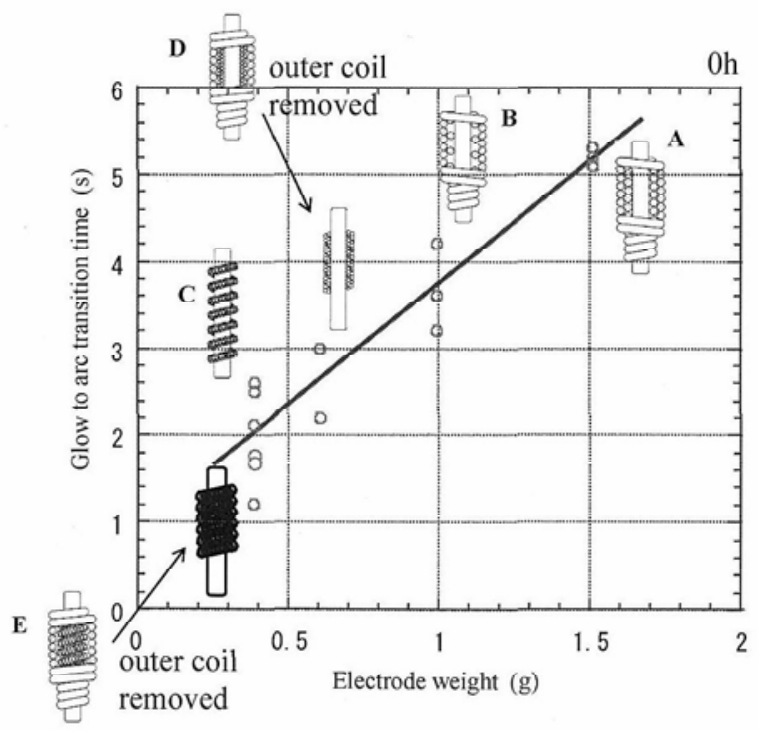

Figure 8 Relationship between electrode weight and glow to arc transition time (outer coils from electrode D \& E were removed)
Figure 7 is the group of electrode D and electrode $\mathrm{E}$ where the emitter is shielded by outer coil.

If the outer-coil is removed from electrode $\mathrm{D}$ and electrode $\mathrm{E}$, the relation showed in Figure 7 is changed to that shown in Figure 8. The weight of electrodes and glow to arc transition time has the linear relation.

Regarding electrode $\mathrm{C}$ and electrode $\mathrm{E}$, the weight of electrode and glow to arc transition time of electrode are nearly the same. However the reason why the variation of lamp voltages during burning of the electrode $\mathrm{C}$ and electrode $\mathrm{E}$ occurred is that emitter with electrode $\mathrm{C}$ was exposed directly to discharge space and was exposed to too high temperature. Cathode fall at ignition will sputter the emitter on the surface of electrode C. By these reasons, emitter evaporated and sputtered from the triple coil during burning. Regarding electrode $\mathrm{E}$, it was estimated that sputtering of emitter was shielded by the outer coil and emitter was cooled as a result, also outer coil seemed to act as a radiator.

These data meets the contents of the book written by Waymouth, J. F.5)

\section{Conclusion}

As is shown above, electrode weight has close relation with lamp-life performance. When the electrode weight was lighter, glow to arc transition time became shorter and life performance became good. However, when the emitter of the lighter weight electrode was exposed directly to the discharge space, severe blackening occurred. The shield coil surrounding the emitter coated coil was needed to get good life performance even with a light weight electrode.

\section{Acknowledgement}

Authors thank Dr. Hiroyuki Mizuno, Dr. Hideo Mizuno, Dr. Tomokazu Kobayashi, Dr. Hidezo Akutsu and Mr. Keizo Kondo. We also thank Mr. Shinya Uemura, Dr. Shigeru Kamiya and Mr. Hiroshi Gion for the application of the electrode to HPS lamps.

\section{References}

(1) Saito, N., Akutsu, H., Kondo, K. and Gion, H.: Electrode construction of high pressure sodium lamp, Proc. of 1997 Annual Conf. of the Illum. Engng. Inst. Jpn., 22 (1997).

(2) Waymouth, J.F.: The Glow-to-thermionic-arc transition, J. of IES Summer, pp.166-180 (1987).

(3) Inoue, A. and Ogawa, K.: Problems of discharge lamp starting, Toshiba Review, 29-2, pp.760-762 (1974).

(4) Brabham, D.E. and Jacobs, C.A.: Ignition and life performance of color improved HPS lamps, Journal 
of IES, Winter, pp.41-46 (1992).

(5) Waymouth, J.F: The Electrodes, in Electric dis charge lamps, The M.I.T. Press Cambridge, MA, p.71 (1971).
(6) Higashi, T., Nagano, S., Inoue, A., Ishigami, T. and Danno, Y: Analysis for raising of lamp voltage with HPS lamp No.1, Proc. of 1981 Annual Conf. of the Illum. Engng. Inst. Jpn., 11 (1979). 